\title{
Disability and Mortality in Convulsive Status Epilepticus in Children at 3 Months' Follow-Up: A Prospective Study from India
}

\author{
Vansha Pathania ${ }^{1}$ Vishal Guglani ${ }^{1}$ Chandrika Azad ${ }^{1}$ () Suksham Jain ${ }^{2}$ Ravinder Kaur ${ }^{3}$ \\ Dharmendra Kumar Singh ${ }^{4}$
}

${ }^{1}$ Department of Paediatrics, Government Medical College and Hospital, Chandigarh, India

${ }^{2}$ Department of Neonatology, Government Medical College and Hospital, Chandigarh, India

${ }^{3}$ Department of Radiodiagnosis, Government Medical College and Hospital, Chandigarh, India

${ }^{4}$ Department of Radiodiagnosis, Vardhman Mahavir Medical College and Safdarjung Hospital, New Delhi, India

\begin{abstract}
Address for correspondence Chandrika Azad, MD, Department of Pediatrics, Government Medical College and Hospital, Chandigarh, India (e-mail: chandrika_azad@yahoo.co.in).
\end{abstract}

J Neurosci Rural Pract 2022;13:211-217.

\section{Abstract \\ Keywords \\ - status epilepticus \\ - child \\ - follow- up studies \\ - prospective studies \\ - developing countries \\ - cause of death \\ - morbidity}

Background Convulsive status epilepticus (CSE) is a common neurological emergency with high mortality, morbidity, and poor quality of life. There is a paucity of followup studies from developing nations in pediatric age group.

Objectives This article looks for clinico-etiological profile of CSE and estimates the immediate and short-term mortality in children with CSE and its predictive factors.

Methodology This prospective longitudinal study was done at a tertiary care institute of Northern India. The patients between the ages of 1 and 16 years with CSE were enrolled after informed consent, they were observed in the hospital, and survived patients were followed till 3 months after discharge.

Results A total of 200 patients (58\% males) were enrolled. Acute symptomatic (63.5\%) was the most common etiology. Twenty-five (12.5\%) patients died during hospital stay; at discharge, 160 (80\%) had good recovery and rest had a varying range of disability. The predictive factors for poor outcome were female gender, duration of CSE $>1$ hour at presentation, generalized seizures, Glasgow Coma Scale $<8$ at presentation, refractory status epilepticus, need for critical care support, and acute symptomatic etiology. On follow-up, two patients died at 1-month and one at 3-month follow-up, the cause of death was probably seizures in two patients and feed aspiration in one patient. Seven patients deteriorated from good recovery scoring to moderate disability during the time interval between first and second follow-up, none of them reported apparent repeat seizures.

Conclusion Pediatric CSE is associated with immediate poor outcome; risk of death and new disabilities persist after discharge thus proper follow-up is essential. published online February 23, 2022
DOI https://doi.org/

$10.1055 / \mathrm{s}-0042-1743212$. ISSN 0976-3147. (c) 2022. Association for Helping Neurosurgical Sick People. All rights reserved.

This is an open access article published by Thieme under the terms of the Creative Commons Attribution-NonDerivative-NonCommercial-License, permitting copying and reproduction so long as the original work is given appropriate credit. Contents may not be used for commercial purposes, or adapted, remixed, transformed or built upon. (https://creativecommons.org/ licenses/by-nc-nd/4.0/)

Thieme Medical and Scientific Publishers Pvt. Ltd., A-12, 2nd Floor, Sector 2, Noida-201301 UP, India 


\section{Introduction}

Convulsive status epilepticus (CSE) is a common pediatric neurological emergency. It predisposes to increased risk of short- and long-term mortality, poor neurocognitive outcome, increased risk of subsequent epilepsy, and repeat CSE. ${ }^{1-4}$ The mortality at discharge in resource-poor countries ranges between 10 and 30\%, whereas in developed nations it is 2 to $7 \% .^{5-8}$ In a review by Sculier et al, long-term mortality after status epilepticus (SE) was noticed up to $20 \%$ in children and $55 \%$ in adults; in older studies mortality was higher whereas in newer studies it was $<5 \% .{ }^{4}$ Pujar et al reported $11 \%$ case fatality rate on 8-year follow-up of childhood CSE. ${ }^{9}$ Around 20 to $50 \%$ patients can have a recurrence of SE, and on long-term follow-up, 37\% can have behavioral and 28\% psychiatric issues. ${ }^{1,10,11}$ The development of epilepsy after SE has been found to be 13 to $74 \%{ }^{1}$ All these factors predispose to poor quality of life in patients and heavy economic burden on families and society. The outcome of pediatric SE mostly depends upon the etiology, SE duration, and age; though some factors operating in determining prognosis are still uncertain. ${ }^{4,10}$

Follow-up studies are scarce from developing nations, especially from the Indian subcontinent. In a study in the adult population, around $70 \%$ patients had seizure recurrence on 1-year follow-up and $22 \%$ were severely dependent for activities of daily living. ${ }^{12}$ We conducted this study to see immediate and short-term outcome in pediatric SE and factors determining the prognosis.

\section{Methodology}

\section{Study Design and Population}

This prospective, single-center, longitudinal study was done at a government medical college of Northern India. The patients were enrolled after getting written informed consent from their parents. The study was conducted over 21 months from January 2017 to October 2018. A convenient sample size of 200 patients was taken.

\section{Inclusion/Exclusion Criteria}

The parents of all patients with CSE between 1 and 16 years of age presenting consecutively to the pediatric emergency or pediatric intensive care unit were asked to participate in the study. The known cases of cerebral palsy or degenerative brain disorder were excluded. Those who refused consent were also excluded.

\section{Study Procedure and Data Collection}

All new patients with CSE, fulfilling inclusion criteria during data collection, were enrolled.

SE definition was taken as per the International League Against Epilepsy 2015 guidelines and $t_{2}$ (status lasting $>30$ minutes) was taken as the time point, since long-term neuronal damage is supposed to occur after this point. ${ }^{13}$ Only patients with CSE were included. Refractory SE was defined as prolonged seizures that did not stop after administration of two antiseizure medications with different mechanisms of action or that need continuous administration of medication to abort seizures, regardless of seizure duration. The following definitions for CSE were considered: prolonged febrile seizures (PFS): SE in a previously neurologically normal child in the age group of 6 months to 5 years during a febrile (temperature $>38^{\circ} \mathrm{C}$ ) illness and no evidence of definite intracranial infection ${ }^{2}$; acute symptomatic CSE: SE in a patient with no previous neurological abnormality, within 7 days of an identified acute neurologic insult, including pyogenic meningitis, viral encephalitis, metabolic abnormalities, drug-related effects, head trauma, hypoxic or anoxic event, or cerebrovascular disease ${ }^{2}$; remote symptomatic CSE: SE without any evidence of an identifiable acute insult but with a history of a preexisting central nervous system abnormality more than 7 days before an episode of $\mathrm{CSE}^{2}$; and Unknown: SE not classifiable into any other group. ${ }^{2,13}$

Clinico-demographic details were recorded on the prespecified case record form. The baseline evaluation at the time of enrolment was done by a physician/study investigator. A structured institutional treatment regime to treat CSE was followed. After taking care of airway, breathing, and circulation, blood sugar levels were checked. Patients with seizure $>5$ minutes duration were given intravenous $0.2 \mathrm{mg} / \mathrm{kg}$ diazepam as bolus dose. If seizure persisted after diazepam, intravenous phenytoin $20 \mathrm{mg} / \mathrm{kg}$ was given in a slow intravenous infusion over 15 to 20 minutes; if there was no response, second loading with phenytoin $10 \mathrm{mg} / \mathrm{kg}$ was given 10 minutes after the first phenytoin loading. Patients in whom, status persisted, loading of $30 \mathrm{mg} / \mathrm{kg}$ valproate was given. If still unresponsive, intravenous levetiracetam $30 \mathrm{mg} / \mathrm{kg}$ was given. In patients with liver dysfunction, valproate was not given. If seizures persisted after this step, either loading of phenobarbitone $20 \mathrm{mg} / \mathrm{kg}$ was given or midazolam bolus 0.2 $\mathrm{mg} / \mathrm{kg}$ followed by $2 \mu \mathrm{g} / \mathrm{kg} / \mathrm{min}$ to maximum of $10 \mu \mathrm{g} / \mathrm{kg} / \mathrm{min}$. After seizures were controlled, the infusion of midazolam was continued for at least 24 hours and then gradually tapered off. The patients with Glasgow Coma Scale (GCS) score $<8$ or breathing difficulty were intubated.

After stabilization, details of developmental history, any coexisting medical diseases, epilepsy, antiepileptic drug (AED) use, and seizure semiology were taken. A detailed physical examination was performed. The laboratory tests including hemogram, random blood sugar levels, serum calcium, serum electrolytes and renal function tests, cerebrospinal fluid analysis, electroencephalography, neuroimaging (computed tomographic scan, magnetic resonance imaging of brain), and screening for metabolic disorders were conducted as per clinician's discretion. During the hospital stay, the outcome, critical care needs, and total stay in hospital were noted. The patients were followed throughout the hospital stay.

Methods of neurological disability assessment: Glasgow Outcome Score (GOS) was used to assess outcome at three points: at discharge, at 1 month, and at 3 months.

At follow-up, patients were called to the hospital; those who refused to come to the hospital were assessed by telephonic interview. 


\section{Outcome Measures}

The primary outcome measures were taken as proportion of patients with CSE having poor outcome (GOS I-IV) at discharge, at 1 month, and 3 months postdischarge, and correlation of GOS score to clinical profile was analyzed.

\section{Statistical Analysis}

Data analysis was done on SPSS version 18. Descriptive data for all study variables were done as mean \pm standard deviation (SD), numbers and percentages, and median and interquartile ranges (IQRs). The categorical and continuous variables were analyzed by chi-square test and independent $t$-test. The mortality/morbidity in the subgroups was reported as the proportion of the sample. The potential influence of confounding variables for poor outcome was looked by a multivariate binomial logistic regression model and results were reported as odds ratios with $95 \%$ confidence intervals. A $p$-value of $<0.05$ was taken as statistically significant.

\section{Ethics}

The study was approved by the institutional ethics committee (Ethical approval number: EC/2016/0054).

\section{Results}

\section{Clinical and Demographic Features}

The mean (SD) age of the patients was 7 (2.9) years and 58\% were males (-Table $\mathbf{1}$ ). Children under 5 years constituted $41 \%$. A very high number of children (both genders) were malnourished ( $p$ 0.97) (-Table 2). Majority (87\%) were immunized as per national immunization schedule. Among the presenting complaints, apart from seizures, fever (49.5\%) and altered sensorium (16.5\%) were main complaints. Sixtyfive percent patients had generalized seizures and 39\% had seizure duration more than 1 hour at presentation. Higher percentage $(47 \%)$ of girls had SE lasting for $>1$ hour $(p 0.0001)$ (-Table 2). Only 24\% patients received nasal/parenteral anticonvulsant at home, from a private practitioner, or from a primary health care center.

At hospital admission, mean (SD) GCS score was 13.75 (2.58). Eleven percent patients had a GCS score $<8$ at presentation (out of them $64 \%$ were girls), $12.5 \%$ had features of raised intracranial pressure, $7.5 \%$ respiratory failure, and $5 \%$ circulatory shock.

Twenty-two percent had normal neuroimaging; $18 \%$ patients had neurocysticercosis, 7.5\% tuberculoma, and 6\% had features of old insult (gliosis, porencephalic cyst), whereas $2.5 \%$ patients had temporal lobe involvement suggestive of herpes simplex encephalitis.

\section{Management}

During hospital stay, $15 \%$ required intubation, $17 \%$ needed respiratory support, $14 \%$ neurocritical care, and 13\% inotropic support. More girls as compared with boys ( $26 \%$ vs. $12 \%$ ) required critical care. Note that $24.5 \%$ patients had remote symptomatic etiology (RSE). Mean (IQR) duration of hospital stay was 6.81 (2-30) days (-Table $\mathbf{1}$ ).
Table 1 Patient characteristics in descriptive analysis

\begin{tabular}{|c|c|}
\hline Variables & $N=200$ \\
\hline Age $(y)$, mean $\pm S D$ & $7.00 \pm 2.9$ \\
\hline Male, $N(\%)$ & $116(58)$ \\
\hline Previous developmental delay, $N(\%)$ & $18(9)$ \\
\hline Past history of seizures, $N(\%)$ & $35(17)$ \\
\hline Malnutrition, $N(\%)$ & $182(91)$ \\
\hline \multicolumn{2}{|l|}{ Presenting features } \\
\hline Fever, $N(\%)$ & $99(49.5)$ \\
\hline Altered sensorium, $N(\%)$ & $33(16.5)$ \\
\hline \multicolumn{2}{|l|}{ Type of seizure } \\
\hline Generalized, $N(\%)$ & $130(65)$ \\
\hline Duration > $1 \mathrm{~h}, N(\%)$ & $78(39)$ \\
\hline Received prehospital treatment, $N(\%)$ & $47(24)$ \\
\hline \multicolumn{2}{|l|}{ Examination findings at presentation } \\
\hline GCS, mean (SD) & $13.75(2.58)$ \\
\hline Unequal pupils, $N(\%)$ & $7(3.5)$ \\
\hline Focal neurological signs, $N(\%)$ & $5(2.5)$ \\
\hline \multicolumn{2}{|l|}{ Need for critical care } \\
\hline Respiratory support, $N(\%)$ & $34(17)$ \\
\hline Neurocritical care, $N(\%)$ & $28(14)$ \\
\hline Inotropic support, N (\%) & $26(13)$ \\
\hline Refractory status, N (\%) & $49(24.5)$ \\
\hline $\begin{array}{l}\text { Duration of hospital stay, (in d), } \\
\text { mean (IQR) }\end{array}$ & $6.81(2-30)$ \\
\hline Case fatality rate, $N(\%)$ & $25(12.5)$ \\
\hline
\end{tabular}

Abbreviations: GCS, Glasgow Coma Scale; IQR, interquartile range; SD, standard deviation.

\section{Etiology}

It was assigned as per the clinical and investigational findings. Out of 200 patients, acute symptomatic etiology (63.5\%) was the most common etiology followed by remote symptomatic in $9 \%$, PFS in $16.5 \%$, and unknown in $10 \%$ cases. Among acute symptomatic etiology, acute intracranial infections were the most common (95\%) (-Supplementary Table S1, available in the online version only). There was no significant difference between etiological distributions between genders (-Table $\mathbf{2}$ ).

\section{Outcome}

The patients were assessed for outcome by GOS at three assessment points, at discharge, at 1 month, and at 3 months.

At discharge, out of 200 patients, 25 (12.5\%) died during hospital stay. Rest of the patients was assessed at discharge for neurological sequelae. Eighty percent had good recovery, 3\% mild disability, $3 \%$ moderate disability, and $1.5 \%$ had persistent vegetative state (-Table 3 ).

\section{Predictive Factors for Poor Outcome at Discharge (-Table 4)}

We grouped GOS 1 to 4 as poor outcome and GOS 5 as good outcome. Patients aged $>5$ years had 1.5 times chances of 
214 Disability and Mortality in Convulsive Status Epilepticus in Children Pathania et al.

Table 2 Gender-wise characteristics of cases

\begin{tabular}{|l|l|l|l|}
\hline & Girls (84) & Boys (116) & $p$-Value \\
\hline Age $<5$ y & $40(47.6)$ & $42(36)$ & 0.10 \\
\hline Malnutrition & $76(90.5)$ & $106(91)$ & 0.97 \\
\hline Anemia & $28(33)$ & $47(40.5)$ & 0.30 \\
\hline Developmental delay & $6(7)$ & $12(10)$ & 0.43 \\
\hline Prehospital treatment & $20(24)$ & $27(23)$ & 0.92 \\
\hline Duration of status ${ }^{\text {a }} 1 \mathrm{~h}$ & $40(47)$ & $38(33)$ & $\mathbf{0 . 0 0 0 1}$ \\
\hline Shock at presentation & $4(5)$ & $6(5)$ & 0.89 \\
\hline GCS $<8$ (at presentation) & $14(17)$ & $8(7)$ & $\mathbf{0 . 0 2 9}$ \\
\hline Refractory status & $20(24)$ & $23(20)$ & 0.49 \\
\hline Critical care needs & $22(26)$ & $14(12)$ & 0.010 \\
\hline Poor outcome at discharge & $26(31)$ & $14(12)$ & 0.0009 \\
\hline Etiology & & & \\
\hline Acute & $60(71)$ & $67(58)$ & \\
\hline Remote & $4(5)$ & $13(13)$ & $21(18)$ \\
\hline Febrile & $7(8)$ & $13(11)$ & 0.141 \\
\hline Unknown & & \\
\hline
\end{tabular}

Abbreviation: GCS, Glasgow Coma Scale.

Note: Boldfaced values are statistically significant $(p<0.05)$.

${ }^{\mathrm{a}}$ At presentation.

Table 3 Outcome at discharge and follow-up

\begin{tabular}{|l|l|l|l|}
\hline $\begin{array}{l}\text { Grading of outcomes } \\
\text { (GOS } \\
\text { score) }\end{array}$ & $\begin{array}{l}\text { Discharge } \\
n(\%)\end{array}$ & $\begin{array}{l}\text { At 1 mo } \\
n(\%) \\
n(\%)\end{array}$ \\
\hline Death (GOS 1) & $25(12.5)$ & $2(1.34)$ & $1(0.8)$ \\
\hline Persistent vegetative state (GOS 2) & $3(1.5)$ & $1(0.67)$ & 0 \\
\hline Severe disability (GOS 3) & $6(3)$ & $6(4)$ & $4(3)$ \\
\hline Moderate disability (GOS 4) & $6(3)$ & $6(4)$ & $12(10)$ \\
\hline Good recovery (GOS 5) & $160(80)$ & $134(90)$ & $106(86)$ \\
\hline Total & 200 & 149 & 123 \\
\hline
\end{tabular}

Abbreviation: GOS, Glasgow Outcome Score.

poor outcome, also girls had more chances of poor outcome ( $p$ 0.0009). Patients with generalized seizures and seizure duration $>60$ minutes had poor outcome ( $p 0.0008$ and $<0.000)$. RSE was likely to cause 15 times more chances of poor outcome in patients as compared with patients without RSE. Patients presenting with GCS $<8$ had 79 times more chances of having poor outcome than who had higher GCS. Requirement of critical care (assisted ventilation/inotropic support/management of raised intracranial pressure) reflecting seriousness of clinical condition was associated with very high chances of poor outcome $(p<0.0000)$. Patients with acute symptomatic etiology had higher chances of mortality and morbidity as compared with all other etiologies clubbed together.
Follow-up: Only 85\% (149/175) patients could be followed up at 1 month and 71\% (123/173) at 3 months (-Table 3 ).

One-month follow-up: Two patients died before the first follow-up, cause was probably aspiration in one and seizures in another (-Table 5). Ninety percent patients had a good recovery, $4 \%$ had moderate and severe disability each, and one patient had a persistent vegetative state (-Table $\mathbf{3}$ ).

Three-month follow-up: Out of 123 contactable patients, one patient was reported dead, the cause of death was probably repeat seizure, $3.3 \%$ patients had severe disability, 9.7\% moderate disability, and $86 \%$ good recovery. Seven patients ( 4 males) deteriorated from GOS 5 to 4 (as compared with follow-up at 1 month), three had acute symptomatic etiology of SE, two unknown etiology, and two patients PFS. 
Table 4 Predictors of poor outcome at discharge

\begin{tabular}{|c|c|c|c|c|}
\hline Variables & $\begin{array}{l}\text { Poor outcome } \\
n(\%)\end{array}$ & $\begin{array}{l}\text { Good outcome } \\
n(\%)\end{array}$ & Odds ratio & $p$-Value \\
\hline Age $<5$ y $(n=82)$ & $13(16)$ & $69(84)$ & $1.54(0.74-3.19)$ & 0.24 \\
\hline Age $>5$ y $(n=118)$ & $27(23)$ & $91(77)$ & & \\
\hline Female $(n=84)$ & $26(31)$ & $58(69)$ & $3.27(1.58-6.75)$ & 0.0009 \\
\hline Male $(n=116)$ & $14(12)$ & $102(88)$ & & \\
\hline Duration of status $<1 \mathrm{~h}(n=122)$ & $12(10)$ & $110(90)$ & $5.13(2.41-10.91)$ & $<0.00001$ \\
\hline Duration of status $>1 \mathrm{~h}(n=78)$ & $28(36)$ & $50(64)$ & & \\
\hline Generalized seizures $(n=130)$ & $35(27)$ & $95(73)$ & $4.78(1.78-12.87)$ & 0.00085 \\
\hline Focal seizures $(n=70)$ & $5(7)$ & $65(93)$ & & \\
\hline Fever at presentation $(n=103)$ & $21(20)$ & $82(80)$ & $1.05(0.53-2.1)$ & 0.88 \\
\hline Afebrile at presentation $(n=97)$ & $19(20)$ & $78(80)$ & & \\
\hline Prehospital treatment $(n=47)$ & $11(23)$ & $36(77)$ & $1.30(0.59-2.87)$ & 0.50 \\
\hline No prehospital treatment $(n=143)$ & $29(20)$ & $114(80)$ & & \\
\hline GCS $<8$ at presentation $(n=22)$ & $20(90)$ & $2(10)$ & $79(17.17-363.44)$ & $<0.00001$ \\
\hline GCS $>8$ at presentation $(n=178)$ & $20(11)$ & $158(89)$ & & \\
\hline Refractory status $(n=49)$ & $28(57)$ & $21(43)$ & $15.44(6.82-34.97)$ & $<0.00001$ \\
\hline Nonrefractory status $(n=151)$ & $12(8)$ & $139(92)$ & & \\
\hline Critical care needed $(n=35)$ & $28(80)$ & $7(20)$ & $51(18.47-140.8)$ & $<0.00001$ \\
\hline No critical care needs $(n=165)$ & $12(7)$ & $153(93)$ & & \\
\hline Acute symptomatic etiology $(n=127)$ & $32(25)$ & $95(75)$ & $2.73(1.19-6.32)$ & 0.0153 \\
\hline Other etiologies $(n=173)$ & $8(5)$ & $65(95)$ & & \\
\hline
\end{tabular}

Abbreviation: GCS, Glasgow Coma Scale.

Note: Boldfaced values are statistically significant $(p<0.05)$.

Table 5 Details of deaths on follow-up

\begin{tabular}{|c|c|c|c|}
\hline & Case 1 & Case 2 & Case 3 \\
\hline Age (y) & 15 & 9 & 11 \\
\hline Gender & Male & Male & Female \\
\hline Past history of seizures & No & Yes & No \\
\hline Developmental delay & No & Yes & No \\
\hline Fever & Yes & Yes & No \\
\hline SE duration & $>1 \mathrm{~h}$ & $<1 \mathrm{~h}$ & $>1 \mathrm{~h}$ \\
\hline Type of seizures & Generalized & Generalized & Focal \\
\hline Prehospital treatment & No & No & Yes \\
\hline Critical care needs & Yes & Yes & Yes \\
\hline Refractory SE & Yes & Yes & Yes \\
\hline Neuroimaging & Basal ganglia hyperintensities & Gliosis & Normal \\
\hline Etiology & Acute symptomatic & Remote symptomatic & Unknown \\
\hline $\begin{array}{l}\text { AED prescribed at } \\
\text { discharge }\end{array}$ & $\begin{array}{l}\text { Phenytoin } \\
+ \text { Levetiracetam }\end{array}$ & Phenytoin & Phenytoir \\
\hline $\cos$ at $d / c$ & $2^{a}$ & 2 & 2 \\
\hline GOS at $1 \mathrm{mo}$ & $1^{b}$ & 1 & 2 \\
\hline Cause of death & Aspiration & Seizure & Seizure \\
\hline
\end{tabular}

Abbreviations: AED, antiepileptic drugs; GOS, Glasgow Outcome Score; SE, status epilepticus.

${ }^{\mathrm{a}} \mathrm{GOS} 2$ : persistent vegetative state.

${ }^{\mathrm{b}} \mathrm{GOS}$ 1: death. 
Table 6 Details of patients who deteriorated from GOS 5 to GOS 4 at 3 months

\begin{tabular}{|l|l|l|l|l|l|l|l|l|l|}
\hline $\begin{array}{l}\text { Age } \\
(\mathrm{y})\end{array}$ & Sex & Fever & PEM & Seizure & GCS & Neuroimaging & RSE & Etiology & $\begin{array}{l}\text { Anticonvulsant } \\
\text { treatment }\end{array}$ \\
\hline 3.5 & M & Yes & Yes & Generalized & 15 & Normal & No & PFS & None \\
\hline 6 & F & No & Yes & Focal & 15 & Tuberculoma & No & AS & Phenytoin \\
\hline 4 & F & No & No & Focal & 15 & NCC & No & AS & Phenytoin \\
\hline 3.5 & M & No & No & Generalized & 15 & MTS & Yes & PFS & $\begin{array}{l}\text { Phenytoin }+ \\
\text { Valproate }\end{array}$ \\
\hline 5 & M & No & Yes & Focal & 15 & Normal & No & Unknown & Phenytoin \\
\hline 3.5 & F & No & No & Focal & 15 & NCC & No & AS & Phenytoin \\
\hline 5 & M & No & Yes & Focal & 15 & Normal & No & Unknown & None \\
\hline
\end{tabular}

Abbreviations: AS, acute symptomatic; F, female; GCS, Glasgow Coma Scale; GOS, Glasgow Outcome Score; MTS, mesial temporal sclerosis; M, male; NCC, neurocysticercosis; PEM, protein energy malnutrition; PFS, prolonged febrile seizures; RSE, remote symptomatic etiology.

One of the PFS patients developed mesial temporal sclerosis (MTS) on repeat neuroimaging at 1-month follow-up. None of these seven patients reported repeat seizures. Five of them were on anticonvulsants (-Table 6).

\section{Discussion}

The present study done on 200 children between 1 and 16 years of age presenting with CSE had a case fatality rate of $12.5 \%$ and $7.5 \%$ morbidity at discharge. Acute symptomatic etiology was seen in $63.5 \%$ cases. Loss to follow-up was seen in $15 \%$ cases at first and $29 \%$ cases at second follow-up. Two deaths at first follow-up and one death at second follow-up were reported, seven patients deteriorated to moderate disability at 3-month follow-up.

The short-term mortality rate in various follow-up studies have been reported as 7 to $17.5 \%$ in resource-poor countries and 2 to $6 \%$ in developed nations. ${ }^{14}$ As per a systemic review done in 2006, the causality of CSE was the most important determinant of death, most in-hospital deaths might not be attributable to the CSE itself. This argument is supported by the significantly lower mortality rate $(0-2 \%)$ of febrile SE or unknown causes as compared with acute or remote symptomatic cases. ${ }^{10}$ In the present study, case fatality rate of $12.5 \%$ was seen at discharge. In various studies, refractory status, acute symptomatic etiology, young age, malnutrition, shock, aspiration, sepsis, near drowning, inadequate prehospital treatment, etc. have been listed as predictors of poor outcome. ${ }^{6,15-19}$ In the present study, female gender, SE duration $>1$ hour before presentation, generalized onset seizures, need for critical care support, poor response to initial antiepileptic therapy, and acute symptomatic etiology were found as predictors of poor outcome.

Girls had a longer duration of SE before admission, poor sensorium, higher chances of requiring critical care support, and poor outcome ( $p$ 0.0009). The poor outcome could be the result of delayed attention sought or physiological factors. A previous study from this center also had higher mortality in females. $^{5}$

Two out of three deaths during follow-up were due to seizures and one due to aspiration. All of them were in a persistent vegetative state at the time of discharge. High follow-up mortality rate in all age groups has been described in various reviews ranging from 10 to 55\%; studies done before widespread availability of modern critical care support and management have higher mortality rate. ${ }^{4}$ In a population-based study by Pujar et al, only $25 \%$ deaths during follow-up were related with seizures whereas rest of the deaths were attributable to the complications of primary medical condition; it was concluded that significant neurological problems before occurrence of CSE were independent risk factor for mortality. ${ }^{9}$

On first follow-up, $90 \%$ of the contactable patients had good outcome, none of the patients deteriorated from good to poor outcome, whereas on second follow-up, seven patients deteriorated from GOS 5 to GOS 4 (-Table 6). The cause of deterioration could be side effects of drugs or unnoticed seizures. Significant deterioration in cognitive functions (e.g., attention, memory, and mental speed) has been seen in persons on phenytoin and phenobarbital in volunteer studies. Other factors which can affect cognition can be polytherapy and high dose of AEDs. ${ }^{20,21}$

This study also enforces the fact that febrile seizures need to be followed up carefully as two patients deteriorated on follow-up and one of them developed MTS. Two patients with unknown etiology also deteriorated, cause could be some underlying etiology, for example, autoimmune encephalitis (AE), which was not picked up by the neuroimaging. We could not get workup done for AE in many cases because of financial constraints.

The present study has several limitations, complete workup could not be done in several cases. There was significant loss to follow-up in the present study, $15 \%$ at 1 month and $29 \%$ at 3 months, making it difficult to accurately assess the outcome. In resource-poor countries, follow-up is a significant problem because of the lack of proper system for it. The health infrastructures are usually overwhelmed with managing emergencies only. Systematic long-term follow-up studies involving field workers with provision for home visit are required for understanding the impact of SE on disability. 


\section{Conclusion}

Childhood CSE patients need to be monitored cautiously after discharge as risk of death and clinical deterioration persists. The patients with poor recovery like in vegetative state/with neurological deficits or frequent seizures might require frequent follow-up (weekly/twice weekly) for parental education regarding feeding/physiotherapy and for drug titration. Many deaths might be prevented by these interventions.

Funding

None.

\section{Conflict of Interest}

None declared.

\section{References}

1 Chin RFM. The outcomes of childhood convulsive status epilepticus. Epilepsy Behav 2019;101(Pt B):106286

2 Chin RFM, Neville BGR, Peckham C, Bedford H, Wade A, Scott RCNLSTEPSS Collaborative Group. Incidence, cause, and shortterm outcome of convulsive status epilepticus in childhood: prospective population-based study. Lancet 2006;368(9531):222-229

3 Martinos MM, Yoong M, Patil S, et al. Early developmental outcomes in children following convulsive status epilepticus: a longitudinal study. Epilepsia 2013;54(06):1012-1019

4 Sculier C, Gaínza-Lein M, Sánchez Fernández I, Loddenkemper T. Long-term outcomes of status epilepticus: a critical assessment. Epilepsia 2018;59(Suppl 2):155-169

5 Arya A, Azad C, Mahajan V, Guglani V. Convulsive status epilepticus in children: a prospective observational study from India. J Pediatr Epilepsy 2020;**:s-0040-s-1712544

6 Sadarangani M, Seaton C, Scott JAG, et al. Incidence and outcome of convulsive status epilepticus in Kenyan children: a cohort study. Lancet Neurol 2008;7(02):145-150

7 Kumar M, Kumari R, Narain NP. Clinical profile of status epilepticus (SE) in children in a tertiary care hospital in Bihar. J Clin Diagn Res 2014;8(07):PC14-PC17
8 Kravljanac R, Jovic N, Djuric M, Jankovic B, Pekmezovic T. Outcome of status epilepticus in children treated in the intensive care unit: a study of 302 cases. Epilepsia 2011;52(02):358-363

9 Pujar SS, Neville BGR, Scott RC, Chin RFMNorth London Epilepsy Research Network. Death within 8 years after childhood convulsive status epilepticus: a population-based study. Brain 2011;134 (Pt 10):2819-2827

10 Raspall-Chaure M, Chin RFM, Neville BG, Scott RC. Outcome of paediatric convulsive status epilepticus: a systematic review. Lancet Neurol 2006;5(09):769-779

11 Shinnar S, Maytal J, Krasnoff L, Moshe SL. Recurrent status epilepticus in children. Ann Neurol 1992;31(06):598-604

12 Sinha S, Prashantha DK, Thennarasu K, Umamaheshwara Rao GS, Satishchandra P. Refractory status epilepticus: a developing country perspective. J Neurol Sci 2010;290(1-2):60-65

13 Trinka E, Cock H, Hesdorffer D, et al. A definition and classification of status epilepticus-report of the ILAE Task Force on Classification of Status Epilepticus. Epilepsia 2015;56(10): $1515-1523$

14 Jafarpour S, Stredny CM, Piantino J, Chapman KE. Baseline and outcome assessment in pediatric status epilepticus. Seizure 2019; 68:52-61

15 Pujar SS, Martinos MM, Cortina-Borja M, et al; North London Epilepsy Research Network. Long-term prognosis after childhood convulsive status epilepticus: a prospective cohort study. Lancet Child Adolesc Health 2018;2(02):103-111

16 Hommady RH, Alrifai MT, Mubayrik OK, et al. Retrospective review of pediatric status epilepticus in 116 Saudi patients: predictors of outcome. Ann Saudi Med 2017;37(06):455-460

17 Loddenkemper T, Syed TU, Ramgopal S, et al. Risk factors associated with death in in-hospital pediatric convulsive status epilepticus. PLoS One 2012;7(10):e47474

18 Asadi-Pooya AA, Poordast A. Etiologies and outcomes of status epilepticus in children. Epilepsy Behav 2005;7(03):502-505

19 Kang DC, Lee Y-M, Lee J, Kim HD, Coe C. Prognostic factors of status epilepticus in children. Yonsei Med J 2005;46(01):27-33

20 Mula M, Trimble MR. Antiepileptic drug-induced cognitive adverse effects: potential mechanisms and contributing factors. CNS Drugs 2009;23(02):121-137

21 Brunbech L, Sabers A. Effect of antiepileptic drugs on cognitive function in individuals with epilepsy: a comparative review of newer versus older agents. Drugs 2002;62(04):593-604 